\title{
Physician Perception and Practice of Electroencephalography in Enugu, South East Nigeria
}

\author{
I. O. Onwuekwe1, N. C. Mbadiwe1" ${ }^{*}$, C. S. Eyisi², B. Ezeala-Adikaibe1, C. J. Onwuekwe ${ }^{3}$ \\ ${ }^{1}$ Department of Medicine, College of Medicine, University of Nigeria Enugu Campus, Enugu, Nigeria \\ ${ }^{2}$ Department of Medicine, University of Nigeria Teaching Hospital, Ituku-Ozalla, Enugu \\ ${ }^{3}$ Department of Family Medicine, University of Nigeria Teaching Hospital, Ituku-Ozalla, Enugu \\ Email: *nkeiruchimbadiwe@gmail.com
}

How to cite this paper: Onwuekwe, I.O., Mbadiwe, N.C., Eyisi, C.S., Ezeala-Adikaibe, B. and Onwuekwe, C.J. (2019) Physician Perception and Practice of Electroencephalography in Enugu, South East Nigeria. Open Journal of Internal Medicine, 9, 35-44.

https://doi.org/10.4236/ojim.2019.92006

Received: April 13, 2019

Accepted: June 27, 2019

Published: June 30, 2019

Copyright (c) 2019 by author(s) and Scientific Research Publishing Inc. This work is licensed under the Creative Commons Attribution International License (CC BY 4.0).

http://creativecommons.org/licenses/by/4.0/

\begin{abstract}
Background: Electroencephalography (EEG) is established for evaluating several acute and chronic medical conditions of neurological basis. In much of Nigeria and Africa, it is largely unavailable and underutilized due to scarcity of neurologists and high costs of the equipment. It offers a relatively simple and efficient way to help manage many encephalopathies if well utilized in trained hands. Aim: This study aimed to determine how physicians practicing in Enugu perceive and utilize electroencephalography routinely. Method: Physicians attending a statewide meeting in Enugu in August 2018 were consecutively recruited and a pretested questionnaire was administered after obtaining prior consent. Sociodemographic data as well as their knowledge, attitude and practice of electroencephalography were documented and analyzed. Results: There were 486 respondents (males 335: females 151) and 345 (71\%) were specialists in various disciplines while 141 (29\%) were general practitioners. Only 7 doctors (1.4\%) claimed ignorance of electroencephalography and 6 (1.2\%) stated it was not useful. Majority, 333 doctors (69.1\%) believed it had no impact on routine patient management. This perception was highest for Dental Surgery (100\%) and lowest for Internal Medicine (23\%) specialists. Most doctors $(425,87.4 \%)$ agreed that neurologists should analyze recordings. Most physicians had no access to electroencephalography (61.7\%) and had no interest in acquiring the machine (50.8\%). Conclusion: Electroencephalography is an underappreciated investigative modality amongst physicians in Enugu, despite a high burden of neurological diseases in the population. More education, training and awareness of its utility are needed for medical students and doctors to reverse the trend.
\end{abstract}




\section{Keywords}

Electroencephalography, Physicians, Practice, Enugu, Nigeria

\section{Introduction}

In 1924, Hans Berger first recorded the electrical activity from the human brain through an intact skull in Germany and called it an encephalogram. This work he published in 1929 [1] [2]. Electroencephalography has been described as "one of the most surprising, remarkable, and momentous developments in the history of clinical neurology" [3]. By 1938, the EEG had become an established neuro-diagnostic tool in much of Europe and America [4].

Established indications for electroencephalography are well known (box) [5].

\begin{tabular}{c}
\hline Indications for electroencephalography \\
Diagnosis of seizure tendency \\
Evaluation of type and location of seizure \\
Evaluation of altered mental state \\
Evaluation of nocturnal or sleep related events \\
Evaluation of prognosis in coma \\
Confirmation of brain death \\
Pre-operative evaluation for epilepsy surgery \\
Monitoring brain function during carotid endarterectomy
\end{tabular}

There is paucity of literature write-ups on studies concerning the knowledge, attitude or perceptions and practice of the use of EEG among health practitioners. However literature review concerning the knowledge and practice of doctors towards epilepsy shows that, although most doctors in their lifetime will provide care for patients with epilepsy [6], most of them do not receive further training in epilepsy [7] and therefore are not confident in managing such patients. As a matter of fact, some doctors consider their training in epilepsy care to be inadequate [8] and therefore may not be to make correct diagnosis or request for the appropriate investigations [9] of which electroencephalography is their chief.

The utilization of EEG has been suboptimal in Africa despite the huge burden of neurological disease. According to data from the World Health Organization, there is a very low physician to patient ratio for the neurosciences in Africa: 1 neurologist to 1 - 2.8 million population (versus 4/100,000 in Europe); 1 psychiatrist to 900,000 population (versus 9/100,000 in Europe) and 1 neurosurgeon to 2 - 6 million population (versus 1/100,000 in Europe). Similarly by 2004, it was estimated that there were only 79 EEG machines in Sub-Saharan Africa (excluding South Africa) [10].

Nigeria is the most populous country in the African continent and the most 
populous black nation in the world. Yet there is no published data from the country on how knowledgeable medical doctors (specialists and general practitioners) are concerning EEG or how they utilize the EEG in their routine clinical practices. This study, set in Enugu, the major city in the South East region of Nigeria, determined the perception and practice in a cohort of physicians who live and practice in the vicinity.

\section{Materials and Methods}

\subsection{Study Area}

This descriptive study was carried out in Enugu, the major city of the South East region of Nigeria which is principally a rain forest environment with the population engaged principally in agriculture, public/civil service and commerce/trading.

\subsection{Study Population}

This comprised medical doctors with their practice in Enugu and adjoining communities attending a mandatory meeting of the state branch of the Nigeria Medical Association. Both general practitioners and specialists in medical/surgical disciplines were in attendance. Informed consent was obtained from all.

\subsection{Study Period}

This study was carried out in August 2018.

\subsection{Sampling Technique}

Total sampling was utilized in recruiting study participants.

\subsection{Instrument}

A structured questionnaire, designed and pre-tested for clarity and adequacy, was utilized to obtain socio-demographic data as well as assess perception and practice towards electroencephalography in the respondents. The questionnaire was designed by OIO, EB and ECS. The result of pre-test for clarity and adequacy was $98.2 \%$ and $98 \%$ respectively. Section 1 of the questionnaire asked sociodemographic such as age, gender, number of years of practice, area of specialization. Section 11 tested the knowledge of the doctors about EEG, while section 111 studied the attitude of the doctors toward EEG. Section IV asked questions that will help to evaluate their practice of EEG.

\subsection{Statistical Analysis}

Analysis was done using IBM Statistical Package for the Social Sciences version 21 (Chicago, Illinois, USA). Descriptive statistics were used to compute means and standard deviations for numerical variables as well as frequencies for nominal and ordinal variables. The relationship between categorical responses and explanatory variables were evaluated using chi-square test. In all statistical tests, a value of $\mathrm{p}<0.05$ was considered significant. 


\section{Results}

A total of 520 questionnaires were deployed and 486 were satisfactorily enrolled for analysis (response rate 93.5\%). There were 335 male and 151 female doctors $(\mathrm{M} / \mathrm{F}=2.2)$ with a mean age of $46.7 \pm 9.6$ years, of which $345(71 \%)$ were specialists while 141 (29\%) were of non-specialist cadre (general practitioners and intern house officers).

The distribution of the types of medical practice of the doctors is shown in Table 1. Only 141 (29\%) were of non-specialist cadre.

As shown in Table 2, despite most doctors being aware of the EEG (479, 98.6\%), there was varying degrees of knowledge of its clinical utility across the cadres with doctors in Internal Medicine/Pathology according most importance to it $(46.5 \% / 60 \%)$ while those in the surgical specialties had the lowest opinion on clinical utility of EEG with dental surgeons being the worst affected (100\%). Interestingly up to $82.1 \%$ of newly qualified intern doctors (House Officers) felt the EEG was not useful. Across all the cadres of doctors, the neurologist was accepted as best suited to interpret EEG recordings.

Less than $40 \%$ of doctors certainly had EEG available as a service in their hospitals of practice. This knowledge was highest for doctors in Internal Medicine (>74\%) but surprisingly lowest for psychiatrists (21.7\%). Though the vast majority of doctors (89.5\%) indicated interest in their centres of practice having an EEG machine, just $45.7 \%$ of respondents viewed this as necessity. Table 3 provides more details.

Table 1. Distribution of types of medical practice of respondents.

\begin{tabular}{|c|c|c|}
\hline Practice type & Number & $\%$ \\
\hline Surgery & 90 & 18.5 \\
\hline Public health & 27 & 5.6 \\
\hline Psychiatry & 23 & 4.7 \\
\hline Paediatrics & 42 & 8.9 \\
\hline Pathology & 5 & 1.0 \\
\hline Ophthalmology & 18 & 3.7 \\
\hline Obstetrics and Gynaecology & 33 & 6.8 \\
\hline Internal Medicine & 43 & 8.8 \\
\hline Haematology & 9 & 1.9 \\
\hline Family Medicine & 8 & 1.6 \\
\hline Dentistry & 3 & 0.6 \\
\hline Anaesthesia & 24 & 4.9 \\
\hline${ }^{*}$ General Practice & 102 & 21.0 \\
\hline${ }^{\star}$ Intern House officers & 39 & 8.0 \\
\hline Total & 486 & 100 \\
\hline
\end{tabular}

${ }^{*}$ non-specialists. 
Table 2. Knowledge and perception about EEG in clinical use across the cadres.

\begin{tabular}{cccccc}
\hline & \multirow{2}{*}{$\begin{array}{c}\text { Not heard } \\
\text { of EEG }\end{array}$} & $\begin{array}{c}\text { EEG has no } \\
\text { impact in patient } \\
\text { management }\end{array}$ & \multicolumn{2}{c}{ Who should interpret EEG } \\
\cline { 4 - 6 } & & Neurologists & All doctors & Not Sure \\
\hline Surgery & $2(2.2)$ & $61(67.8)$ & $83(92.2)$ & $4(4.4)$ & $3(3.3)$ \\
Radiology & - & $11(55)$ & $18(90)$ & $1(5)$ & $1(5)$ \\
Public health & - & $20(74.1)$ & $25(92.6)$ & $2(7.4)$ & - \\
Psychiatry & - & $14(60.9)$ & $18(78.3)$ & $3(13)$ & $2(8.7)$ \\
Paediatrics & - & $34(81)$ & $41(97.5)$ & - & - \\
Pathology & - & $2(40)$ & $5(100)$ & - & - \\
Ophthalmology & - & $12(66.7)$ & $13(71.1)$ & $5(27.8)$ & - \\
Obstetrics and & - & $26(78.8)$ & $31993.9)$ & $2(6.1)$ & - \\
Gynaecology & & & & & \\
Internal Medicine & - & $23(53.5)$ & $38(88.4)$ & $3(7)$ & $2(4.7)$ \\
Haematology & $1(11.1)$ & $8(88.9)$ & $8(88.4)$ & $1(11.1)$ & - \\
Family Medicine & - & $6(75)$ & $7(87.5)$ & $1(12.5)$ & - \\
Dentistry & - & $3(100)$ & $3(100)$ & - & - \\
Anaesthesia & - & $18(75)$ & $19(79.2)$ & $5(20.8)$ & - \\
GP & $2(2)$ & $66(64.7)$ & $86(84.3)$ & $11(10.8)$ & $5(4.9)$ \\
House Officers & $2(5.1)$ & $32(82.1)$ & $30(76.9)$ & $6(15.4)$ & $3(7.7)$ \\
& $7(1.4)$ & $336(69.1)$ & $425(87.4)$ & $44(9.1)$ & $17(3.5)$ \\
\hline
\end{tabular}

Table 3. Exploring availability and need for EEG service.

\begin{tabular}{|c|c|c|c|c|c|c|c|c|}
\hline & \multicolumn{3}{|c|}{ Need EEG in my center } & \multicolumn{3}{|c|}{$\begin{array}{l}\text { I would like my center to } \\
\text { get an EEG }\end{array}$} & \multicolumn{2}{|c|}{$\begin{array}{l}\text { My center has an } \\
\text { EEG machine }\end{array}$} \\
\hline & Yes & No & Not sure & Yes & No & Not sure & Yes & No \\
\hline Surgery & $41(45.6)$ & $48(53.3)$ & $1(1.1)$ & $79(87.8)$ & $8(18.9)$ & $3(3.3)$ & $21(23.3)$ & $69(76.7)$ \\
\hline Radiology & $9(45)$ & $10(50)$ & $1(5)$ & $19(95)$ & - & $1(5)$ & $9(45)$ & $11(55)$ \\
\hline Public health & $14(51.9)$ & $13(48.1)$ & - & $24(88.9)$ & $3(11.1)$ & - & $11(40.7)$ & $16(59.3)$ \\
\hline Psychiatry & $6(26.1)$ & $15(65.2)$ & $2(8.7)$ & $21(91.3)$ & - & $2(9.7)$ & $5(21.7)$ & $18(78.3)$ \\
\hline Paediatrics & $18(42.9)$ & $19(45.2)$ & $5(11.9)$ & $34(81)$ & $5(11.9)$ & $3(7.1)$ & $25(59.5)$ & $17(40.5)$ \\
\hline Pathology & $4(80)$ & $1(20)$ & - & $4(100)$ & $1(20)$ & - & $3(60)$ & $2(40)$ \\
\hline Ophthalmology & $11(61.1)$ & $5(27.8)$ & $2(11.1)$ & $16(88.9)$ & $1(5.6)$ & $1(5.6)$ & $7(38.9)$ & $11(61.1)$ \\
\hline $\begin{array}{l}\text { Obstetrics and } \\
\text { Gynaecology }\end{array}$ & $13(39.4)$ & $20(60.6)$ & - & $31(93.9)$ & $2(6.1)$ & - & $14(42.4)$ & $19(57.6)$ \\
\hline $\begin{array}{l}\text { Internal } \\
\text { Medicine }\end{array}$ & $19(44.2)$ & $22(51.2)$ & $2(4.7)$ & $41(95.3)$ & - & $2(4.7)$ & $32(74.4)$ & $11(25.6)$ \\
\hline Haematology & $3(33.3)$ & $6(66.7)$ & - & $9(100)$ & - & - & $5(55.6)$ & $4(44.4)$ \\
\hline $\begin{array}{l}\text { Family } \\
\text { Medicine }\end{array}$ & $6(75)$ & $2(25)$ & - & $8(100)$ & - & - & $3(37.5)$ & $5(62.5)$ \\
\hline Dentistry & $2(66.7)$ & $1(33.3)$ & - & $3(100)$ & - & - & $1(33.3)$ & $2(66.7)$ \\
\hline Anaesthesia & $9(37.5)$ & $15(62.5)$ & - & $23(95.8)$ & $1(4.2)$ & - & $13(54.2)$ & $11(45.8)$ \\
\hline GP & $48(47.1)$ & $52(51)$ & $2(2)$ & $88(86.3)$ & $10(9.8)$ & $4(3.9)$ & $12(80)$ & $83(81.4)$ \\
\hline \multirow[t]{2}{*}{ House Officers } & $19(48.7)$ & $18(46.2)$ & $2(5.1)$ & 35 (89.7) & $3(7.7)$ & $1(2.6)$ & $29(74.4)$ & $21(53.8)$ \\
\hline & $222(45.7)$ & $247(50.8)$ & $17(3.5)$ & $435(89.5)$ & $34(7)$ & $17(3.5)$ & $186(38.3)$ & $300(61.7)$ \\
\hline
\end{tabular}


Reviewing individual physician experience with EEG, about one in three doctors (34\%) have ever witnessed an EEG recording in progress while about $60 \%$ of the doctors have seen an EEG report for a patient. Internal Medicine physicians performed best in this category. Table 4 illustrates these findings across the cadre.

As demonstrated in Table 5, less than half (40.5\%) of all responding doctors had requested for EEG as part of diagnostic workup of their patients in the prior 1 year with a similar proportion (43.5\%) having never made a request for more than half a decade. Subgroup analysis shows that pediatricians had the most recent requests for EEG (84.2\%).

Most of the doctors $(339,85.2 \%)$ correctly named seizures/epilepsy as an indication for EEG while an array of other suitable and unsuitable medical conditions were listed too as shown in Table 6.

Table 4. Assessing physicians' personal experiences with EEG.

\begin{tabular}{ccccc}
\hline & \multicolumn{2}{c}{ I have observed an EEG recording. } & \multicolumn{2}{c}{ I have seen an EEG report } \\
\cline { 2 - 5 } & Yes & No & Yes & No \\
\hline Surgery & $20(22.2)$ & $70(77.8)$ & $47(52.2)$ & $43(47.8)$ \\
Radiology & $4(20)$ & $16(80)$ & $7(35)$ & $13(65)$ \\
Public health & $11(40.7)$ & $16(80)$ & $15(55.6)$ & $12(44.4)$ \\
Psychiatry & $17(73.9)$ & $6(26.1)$ & $21(91.3)$ & $2(78.7)$ \\
Paediatrics & $16(38.1)$ & $26(61.9)$ & $39(92.9)$ & $3(7.1)$ \\
Pathology & $2(40)$ & $3(60)$ & $4(80)$ & $1(20)$ \\
Ophthalmology & $7(38.9)$ & $11(61.1)$ & $7(38.9)$ & $11(61.1)$ \\
Obstetrics and & $9(27.3)$ & $24(72.7)$ & $13(39.4)$ & $20(60.6)$ \\
Gynaecology & $23(53.5)$ & $20(46.5)$ & $34(79.1)$ & $9(20.9)$ \\
Internal Medicine & $4(44.4)$ & $5(55.6)$ & $7(77.8)$ & $2(22.2)$ \\
Haematology & $1(12.5)$ & $7(87.5)$ & $6(75)$ & $2(25)$ \\
Family Medicine & $1(33.3)$ & $2(66.7)$ & $3(100)$ & - \\
Dentistry & $8(33.3)$ & $16(66.7)$ & $10(41.7)$ & $14(58.3)$ \\
Anaesthesia & & & & \\
\hline
\end{tabular}

Table 5. Time of physician's last request for an EEG.

\begin{tabular}{cccccc}
\hline Specialty & $<6$ months & $\mathbf{6}$ months -1 year & $\mathbf{1}-\mathbf{5}$ years & $>5$ years & Total \\
\hline Surgery & $2(2.7)$ & $2(2.7)$ & $14(19.2)$ & $55(75.3)$ & 73 \\
Radiology & $1(7.7)$ & $1(7.7)$ & - & $11(84.6)$ & 13 \\
Public health & $2(8)$ & $4(16)$ & $5(20)$ & $14(56)$ & 25 \\
Psychiatry & $17(81)$ & $1(4.8)$ & $2(9.5)$ & $1(4.8)$ & 21 \\
Paediatrics & $32(84.2)$ & $3(7.9)$ & $2(5.3)$ & $1(2.6)$ & 38 \\
Pathology & $2(50)$ & - & - & $2(50)$ & 4 \\
Ophthalmology & $1(6.3)$ & - & $1(6.3)$ & $12(75)$ & 16 \\
\hline
\end{tabular}




\section{Continued}

\begin{tabular}{cccccc}
\hline Obstetrics and & $4(14.3)$ & $1(3.6)$ & $9(32.1)$ & $14(50)$ & 28 \\
Gynaecology & $17(41.5)$ & $8(19.5)$ & $7(17.1)$ & $9(22)$ & 41 \\
Internal Medicine & - & - & - & $8(100)$ & 8 \\
Haematology & $5(71)$ & - & $1(14.3)$ & $1(14.3)$ & 7 \\
Family Medicine & - & - & - & $1(100)$ & 1 \\
Dentistry & - & $2(10)$ & $4(25)$ & $14(70)$ & 20 \\
Anaesthesia & $36(35.3)$ & $20(19.6)$ & $17(16.7)$ & $29(28.4)$ & 102 \\
General Practice & $2(66.7)$ & $1(33.3)$ & - & - & 3 \\
House officers & $121(30.1)$ & $42(10.4)$ & $64(15.9)$ & $175(43.5)$ & $402(100)^{*}$ \\
Total & & &
\end{tabular}

*84 participants did not answer the question.

Table 6. Physician- given indications for requesting EEG.

\begin{tabular}{cc}
\hline Indications for EEG & Doctors (\%) \\
\hline Seizure/epilepsy & $339(85.2)$ \\
Head injury & $12(3)$ \\
Stroke & $10(2.5)$ \\
Cerebral palsy & $7(1.8)$ \\
Psychiatric disorders & $11(2.9)$ \\
Heart failure/heart disease & $4(1.1)$ \\
Dementia & $3(0.8)$ \\
Other neurologic disorders & $3(0.8)$ \\
Sleep disorders & $2(0.5)$ \\
Hypertension & $2(0.5)$ \\
Chest pain & $2(0.5)$ \\
Loss of consciousness & $1(0.3)$ \\
Autism & $1(0.3)$ \\
Amitriptyline overdose & $1(0.3)$ \\
Total & $398(81.9)$
\end{tabular}

${ }^{*} 88$ participants did not respond to this question.

\section{Discussion}

Despite the advent of high resolution anatomic imaging modalities such as the magnetic resonance imaging (MRI), computed tomography (CT) scan and positron emission tomography (PET), the EEG continues to be a valid tool for research and diagnosis. It is one of the few mobile techniques available and offers millisecond range temporal resolution, a property that is not possible with MRI, CT and (PET) [11]. From the EEG can be derived evoked potentials (EP) and event-related potentials (ERPs) which are techniques that are used in neurology and other neuroscience fields [12] [13].

There is a dearth of literature on the knowledge, attitude and practice of physicians towards the EEG especially in Africa, probably explained by the fact that though the EEG's place in medical practice has been established for decades in much of the developed world, its role in the continent and indeed much of the developing countries has been severely hampered by both lack of equipment and 
extremely few neurologists in those areas [10] [14].

This study is the first one in the South East region of Nigeria to evaluate medical doctors and the contribution of electroencephalography as a diagnostic tool. The cohort assessed comprised a broad range of both specialist and non-specialist cadres of physicians ( $71 \%$ vs $29 \%$ respectively) with surgical consultants (surgery, ophthalmology, obstetrics/gynaecology, dentistry and anesthesia) making up nearly half of the specialists surveyed (48.6\%).

Most physicians interviewed (85.2\%), correctly identified seizures/epilepsy as indications for EEG. This proportion is important considering the high incidence of epilepsy in the African region [10] [14]. It however sharply contrasts with the findings from Laos PDR where only $38.8 \%$ of physicians regarded EEG as relevant in epilepsy management [8]. However in terms of this knowledge being transferred to practice, there was a disparity as only $42 \%$ of all doctors have had cause to refer for EEG in the last $1-10$ years. It could be that this is a reflection of the type of practice as most Pediatricians (84.5\%) and Psychiatrists (81\%) were more conversant with routine referrals, perhaps reflecting the doctors who experience greater exposure to EEG requiring patients including those with epilepsy/seizures.

Physicians generally had poor exposure to EEG with only $34 \%$ ever having witnessed a recording even as medical students. For decades there was a paucity of neurologists in the region and only one institution had an EEG machine. This could explain the rather unsatisfactory level of exposure. Of recent there has been a slight increase in the number of neurologists and greater efforts in medical education at both undergraduate and postgraduate levels in neurology are being made which should hopefully change the narrative over time. The drawback to these efforts are mainly institutional as evidenced by the fact that most hospitals lack access to EEG (61.7\%) and surprisingly nearly half of the physicians $(46.7 \%)$ did not believe EEG was needed in their centres.

Interestingly despite this low level of exposure, most doctors have seen a patient's EEG report (60\%) and nearly all doctors (87.4\%) believe only the neurologist is competent to interpret the EEG. There appears to be a consistent line of disparity in the appreciation of the EEG across the cadres with general practitioners performing worse than specialists in all assessments regarding utility of the EEG, while the surgical specialists (surgery, ophthalmology, obstetrics/gynaecology, dentistry etc.) are out-performed by their medical specialist counterparts (internal medicine physicians, pediatricians, psychiatrists etc.) in knowledge, attitude and practice towards the EEG.

Currently, electroencephalography (EEG) is the most effective diagnostic tool for non-convulsive seizures (NCS) and non-convulsive status epilepticus (NCSE) in intensive care units (ICUs) and emergency departments [5] [11]. Meanwhile, it was estimated that less than two percent of the critically ill patients in ICUs and EDs undergo EEG [15]. Despite this established fact, an uncomfortable majority of anesthetists surveyed here (75\%) were of the opinion that EEG was irrelevant in their routine practice. This finding should be a matter of concern for hospital 
administrators as anesthetists (as intensivists) are usually the personnel who oversee ICUs in hospitals across the region.

The under-adoption or decreased utilization of EEG originates from challenges to accommodate EEG into established practice protocols. General practitioners had been reported to have less awareness and more negative attitudes towards epilepsy [15] and this could well be the case in this region where epilepsy remains the commonest indicator for EEG. In communities in Nigeria, most patients with EEG requiring conditions are more likely to be attended to at the initial visit to a hospital or health centre by general practitioners.

\section{Limitation}

One of the limitations of this study is the limited number of study participants. Not all the medical practitioners in Enugu state could be reached at the time of the study. Only those who attended the meeting of the state chapter of the Nigerian Medical and Dental Association participated in the study, and even then only those that gave their consent were recruited.

Secondly, there are no previous similar studies on the topic of this manuscript done locally, in Africa and generally on the international platform. Therefore literature search on EEG studies did not yield much to form a basis for comparison, hence the scanty literature review of this paper.

\section{Conclusion}

This study has demonstrated that electroencephalography is an under-appreciated investigative modality amongst physicians in Enugu, despite the high burden of neurological diseases in the population. More and continuous educational activities on the utility of EEG are needed for medical students and doctors to reverse the trend.

\section{Acknowledgements}

The authors are grateful to Dr. Maxwell Nnamdi who assisted with the logistics of data collection.

\section{Authors' Contributions}

OIO and ECS conceived and designed the study as well as supervised the data collection. Data analysis was by EB and OIO. OIO and MNC wrote the manuscript. All the authors approved the final draft. Funding was provided by OIO, ECS, OCJ, MNC and EB. OIO is the guarantor of the manuscript.

\section{Conflicts of Interest}

The authors declare no conflicts of interest regarding the publication of this paper.

\section{References}

[1] Brazier, M.A.B. (1960) The Electrical Activity of the Nervous System. 2nd Edition, 
Pitman Medical Publishing, London.

[2] Millet, D. (2002) Origins of EEG. Seventh Annual Meeting of the International Society for the History of the Neurosciences (ISHNS). Los Angeles, California, USA.

[3] Wiedemann, H.R. (1994) Hans Berge. European Journal of Pediatrics, 153, 705. https://doi.org/10.1007/BF01954482

[4] Neuroscience Clerkship (2004) Electroencephalography. Department of Neurology, Case Western Reserve University, Cleveland. http://casemed.case.edu/clerkships/neurology/NeurLrngObjectives/EEG.htm

[5] Vancini, R., Benedito-Silva, A.A., Sousa, B.S., Gomes da Silva, S., MaSouza-Vancini, M.I. and Vancini-Campanharo, C.R. (2012) Knowledge about Epilepsy among Health Professionals: A Cross-Sectional Survey in Sao Paulo, Brazil. British Medical Journal Open, 2, e000919. https://doi.org/10.1136/bmjopen-2012-000919

[6] Sanya, E.O. and Musa, T. (2005) Attitude and Management of Epilepsy-The Perspective of Private Practitioners. Nigerian Medical Practitioner, 516, 130-133.

[7] Harimanana, A., Chivorakul, P., Souvong, V., Preux, P.M. and Barennes, B. (2013) Is Insufficient Knowledge of Epilepsy the Reason for Low Levels of Healthcare in the Lao PDR? BioMed Central Health Services Research, 13, 41. https://doi.org/10.1186/1472-6963-13-41

[8] Gomes, M. (2000) Doctors' Perspectives and Practices Regarding Epilepsy. Arquivos de Neuro-Psiquiatria, 58, 221-226.

https://doi.org/10.1590/S0004-282X2000000200003

[9] Epilepsy in the WHO African Region-Bridging the Gap (2004) Joint Publication of World Health Organization and International Bureau of Epilepsy. WHO African Regional Office, Brazzaville, 30-35.

[10] Hämäläinen, M., Hari, R., Ilmoniemi, R.J., Knuutila, J. and Lounasmaa, O.V. (1993) Magnetoencephalography-Theory, Instrumentation, and Applications to Noninvasive Studies of the Working Human Brain. Reviews of Modern Physics, 65, 413-497. https://doi.org/10.1103/RevModPhys.65.413

[11] Yang, H., Ang, K.K., Wang, C., Phua, K.S. and Guan, C. (2016) Neural and Cortical Analysis of Swallowing and Detection of Motor Imagery of Swallow for Dysphagia Rehabilitation-A Review. Progress Brain Research, 228, 185-219. https://doi.org/10.1016/bs.pbr.2016.03.014

[12] Jestrović, I., Coyle, J.L. and Sejdić, E. (2015) Decoding Human Swallowing via Electroencephalography: A State-of-the-Art Review. Journal Neural Engineering, 12, Article ID: 051001. https://doi.org/10.1088/1741-2560/12/5/051001

[13] Meinardi, H., Scott, R.A. and Reis, R. (2008) The Treatment Gap in Epilepsy: The Current Situation and Ways Forward. Epilepsy, 42, 136-149. https://doi.org/10.1046/j.1528-1157.2001.32800.x

[14] Luan, B. (2018) Single-Unit Leadless EEG Sensor. Doctoral Dissertation, University of Pittsburg, Pittsburg. http://d-scholarship.pitt.edu/id/eprint/33387

[15] Elliott, J. and Shneker, B. (2008) Patient, Caregiver, and Health Care Practitioner Knowledge of, Beliefs about, and Attitudes toward Epilepsy. Epilepsy and Behavior, 12, 547-556. https://doi.org/10.1016/j.yebeh.2007.11.008 